\title{
A Multi-ontology System for Modeling the Information Flow in a Warehouse
}

\author{
Hajira Bakkali \\ Abdellah Azmani \\ Abdelhadi Fennan \\ Laboratory of Sciences Computer, Systems and Telecommunication (LIST) \\ Faculty of Science and Technology (FST) \\ University of Abdelmalek Essaadi Tangier, Morocco
}

\begin{abstract}
The following article proposes an information flow modeling within a warehouse using ontologies. Ontologies consist of facilitating communication and ensuring an understanding of contents of the exchanged messages between the system's agents and the domain actors. This article aims at developing ontologies that describe the inner functioning of the warehouse in order to structure the vast amount of information and make it sharable and automatically treatable by the different entities of the system.
\end{abstract}

\section{General Terms}

Decision support, Artificial Intelligence, Logistics.

\section{Keywords}

Warehouse, Ontologies, Information Flow.

\section{INTRODUCTION}

The warehouse is one of the major links in the supply chain; it plays a vital role in improving firms profitability and customer satisfaction [1]. In fact, the performance of the entire supply structure depends on the efficiency of warehousing logistics [2], consequently, optimizing warehouse operations [3] and organization [4] improves the productivity of the entire supply chain and reduces its costs.

In this perspective, we seek to develop a decision support tool which optimizes the operational functions of a warehouse taking into account different physical flows [5] and information passing through.

Information presents a know-how heritage and grey matter for a company [6], it is considered a strategic resource long as raw materials and energy. In this sense, the control of the information chain within a warehouse is essential in terms of improving productivity. It allows better information reuse as well as structuring the work of trades and exchanging with supply chain partners [7].

In this context, ontologies present a powerful tool of modeling for obtaining rich models in semantics and interoperable thanks to their possibilities of expressivity and reasoning.

This work proposes a multi-ontologies system for modeling information flows within a warehouse.

\section{STATE OF THE ART ON ONTOLOGIES}

Ontological engineering is a new field that can respond to the need of organizing and structuring content in different areas.

In this section, we begin with the definition of ontology, then we tackle the construction methodology, subsequently we specify the purpose of their exploitation and the application fields.

\subsection{Definition}

the word ontology is a Greek word composed of two words "ontos" meaning what exists , and "logos" means study, discourse, from where its translation: the study of Being. [8] However, the term does not have an agreed definition in the literature of artificial intelligence, there are several definitions, the most common is: "Ontology is a formal representation, expressed, referenceable and consensus of all the concepts shared from one domain in terms of classes of belonging and ownership characteristics". [9]

\subsection{Construction methodology}

The engineering knowledge research has indicated that there is no general methodology for constructing ontologies, however, several principles and mechanisms have been proposed by the authors to facilitate the construction [10], [11], [12], [13].

The analysis of these works allows some consensus on the process of building an ontology that is based on three main steps: conceptualization, operationalization, and ontologization.

- Conceptualization: identification of knowledge from different kinds of data such as terms glossaries, other ontologies, text, interviews, etc.

- Ontologization : formalization of the conceptual model obtained in the previous step

- Operationalization : coding the ontology using a representation language of operational knowledge

The different construction methods proposed in the literature can be classified into two categories: construction methods from texts, [14], and construction methods from existing resources (reuse of existing ontologies) [15].

In this article, we modeled our ontologies based on the construction method from texts.

\subsection{Utility of ontologies}

Multiple researches [16], [17], [18], and [19] have studied the utility of ontologies; they are used for:

- Represent the domain knowledge: ontologies describe the objects in a domain, their properties and their relationships, for example [20] proposes ontology for modeling information throughout the product life cycle.

- Facilitate communication: the ontology may be involved in the communication between machines, between humans and machines or between programs. They serve to create a common 
conceptual vocabulary within a group or organization.

- Interoperability: Interoperability is a communication specialization that allows identifying concepts that applications can exchange even if they are distant and developed on a different basis.

- Reuse of knowledge models: ontologies of a given domain can be made available and web shared, and adapted to a new application of the same domain by adding new instances or specific information [21].

- Improve information search process: in the semantic web, ontologies are used to determine the conceptual index describing the resources on the web; we can overcome the keywords approaches by focusing on the concepts used by the user or by providing degraded answers.

\subsection{Application areas}

Currently ontologies present the heart of many applications, we present some ones:

- Enterprise applications: Ontologies are used in the firms' applications to capitalize information and mutualize data; the TOVE project (Toronto Virtual Enterprise), which aims at providing a corporate terminology that is shared by multiple enterprise applications (engineering, manufacturing, marketing, etc.) [22]. Charles proposed ontologies based methodology for constructing the various firms' repositories (competency framework, missions, crafts...) [23].In the field of e-recruitment, [24] offers the conceptualization of an application based on ontology for staffing services.

- $\quad$ The e-commerce area [25]: ontologies are used to personalize customer relationship according to an associated profile [26] and available services in order to guide purchases or after sales service. Ontologies are also used in the support of business processes (Business Process Management, workflows). The authors [27] propose an example of ontology to support the negotiation of Electronic Commerce.

- The e-Learning area: Ontologies facilitate the access to educational resources on the web to help students and teachers easily find what they search [28], [29], [30].

- The medical area: Ontologies are used for biomedical [31], monitoring [32] and telemedicine [33].

- The physical domain: PhysSys ontology was built to assist engineers in developing applications for the dynamic physical systems [34]. PhysSys uses the EngMath ontology, which covers all the aspects related to the mathematical modeling in engineering [35].

- The language area: the PANGLOSS system translates any text from Spanish into English [36], it uses the SENSUS ontology that contains 70,000 concepts and relationships. The Mikrokosmos system translates into English articles written in Spanish or Chinese. Its ontology contains 8000 concepts [37].

- Life sciences: especially in bio-informatics [38].

\section{DESCRIPTION DE FONCTIONNEMENT DE L'ENTREPOT}

The operation in the warehouse is based on four main operations: reception, storage, order preparation and shipping:

- Reception: the first step in the goods receipt process is discharging using different handling machines. After this operation, goods pass through: quantitative and qualitative control to verify the correspondence between the delivery order and the departure issued command. Next, goods follow a labeling process, and are moved to the storage area.

- Storage: the storage operation involves assigning the received goods to the appropriate location according to their characteristic (nature, size, rotation, influence of the environment, etc.). This operation enables to the goods retention for later use (utilization in the production process or incorporation of controls).

- Command Preparation: after receiving a customer order, the demanded quantity of goods is removed from the storage area by the aid the human resources and handling equipment (truck, trolley,... etc.). They are then transmitted to the order preparation area for sorting and packing. Finally, the order is moved to the shipping area.

- Shipping: this operation includes departure pending, goods loading in transport and delivery to the end customer.

\section{PROPOSED APPROACH}

We have chosen to model the information flow in the warehouse using the ontologies, because they facilitate the internal communication with the system and external communication between the different actors of the area. Ontologies are based on concepts and relationships between these concepts to organize and structure the huge amount of information. Warehouse operation description, allowed us to identify the following concepts: warehouse, supplier, customer, order, Good, product, resources and transportation. We have two ways to build ontologies, either we build a single ontology that brings together the various concepts as classes, or we built eight ontologies, each one shows in detail the terms previously identified.

We chose the second solution because it allows us to have:

- A distributed ontological system;

- The possibility of a more streamlined update to develop and integrate, as each ontology is designed separately;

- Reusability because ontology may appear in some other processes

For the development of each ontology, it is proposed to follow the sequence below:

- The textual description of each ontology for the enumeration of important terms;

- The definition of classes and their hierarchy;

- Editing ontologies under the software Protégé 2000 version 4.3

\section{PRESENTATION OF THE DEVELOPED ONTOLOGIES}

For an overview, we start with a presentation of the developed ontologies and their interrelationships (Error! Reference

source not found.). The proposed system contains eight ontologies that interact with each other: warehouse ontology, customer ontology, supplier ontology, transport ontology, 
order ontology, merchandise ontology, product ontology and resources ontology.

\subsection{Customer ontology}

The client ontology (Figure 2) is an ontology that defines the terminology needed to describe customers. The customer is an actual or potential purchaser of merchandise or services offered by a company, it may be a moral or individual person it has several characteristics:

- Confidence: the literature reveals different definitions of the concept of trust. Swan et al [39] define trust as "Client belief that it can rely on what is said or promised by the seller";

- Satisfaction: the satisfaction of the client is determined by both customer expectations and perceived performance of service;

- Fidelity: fidelity of a customer can be defined as a preferential or exclusive enduring attachment to a company or brand;

- Buying behavior: according to Wikie [40] customer behavior is the set of mental, emotional and physical activities in which individuals engage to choose, buy or use a product or service to meet their needs and their desires;

- Needs: the needs are craving, dissatisfaction that drives an individual to wish a product. Maslow [41] has classified these needs into five types according to a Pyramid model: physiological needs, safety needs, belonging needs, esteem needs and selffulfillment needs.

- Customer Expectations: customer expectations can be defined as a set of latent needs of a client who may not find a way to express themselves through direct channel communication. Professor Noriaki Kano [42] defines three types of customer expectations: Basic Expectations, proportional expectations and attractive expectations.

The client ontology is an ontology that defines customer profiles by modeling their preferences, their types, and their personal information. Also, it allows the description of their status (active, inactive, passive, dormant, or captive). The customer practices several activities, it analyzes the offer by selecting items and comparing prices in order to buy goods or pay for services.

\subsection{Supplier ontology}

Ontology provider (Figure 3) is an ontology that defines the terminology needed to describe suppliers. The supplier may be a natural person or a legal person that provides an individual or a company with goods it manufactures or turn controlled products, or it exercised in import or sale of these products.

The commercial features for selecting suppliers are: the willingness and ability to share the risks of the market, continuous performance, systems capacity or service facilities, financial health, location, and certifications.

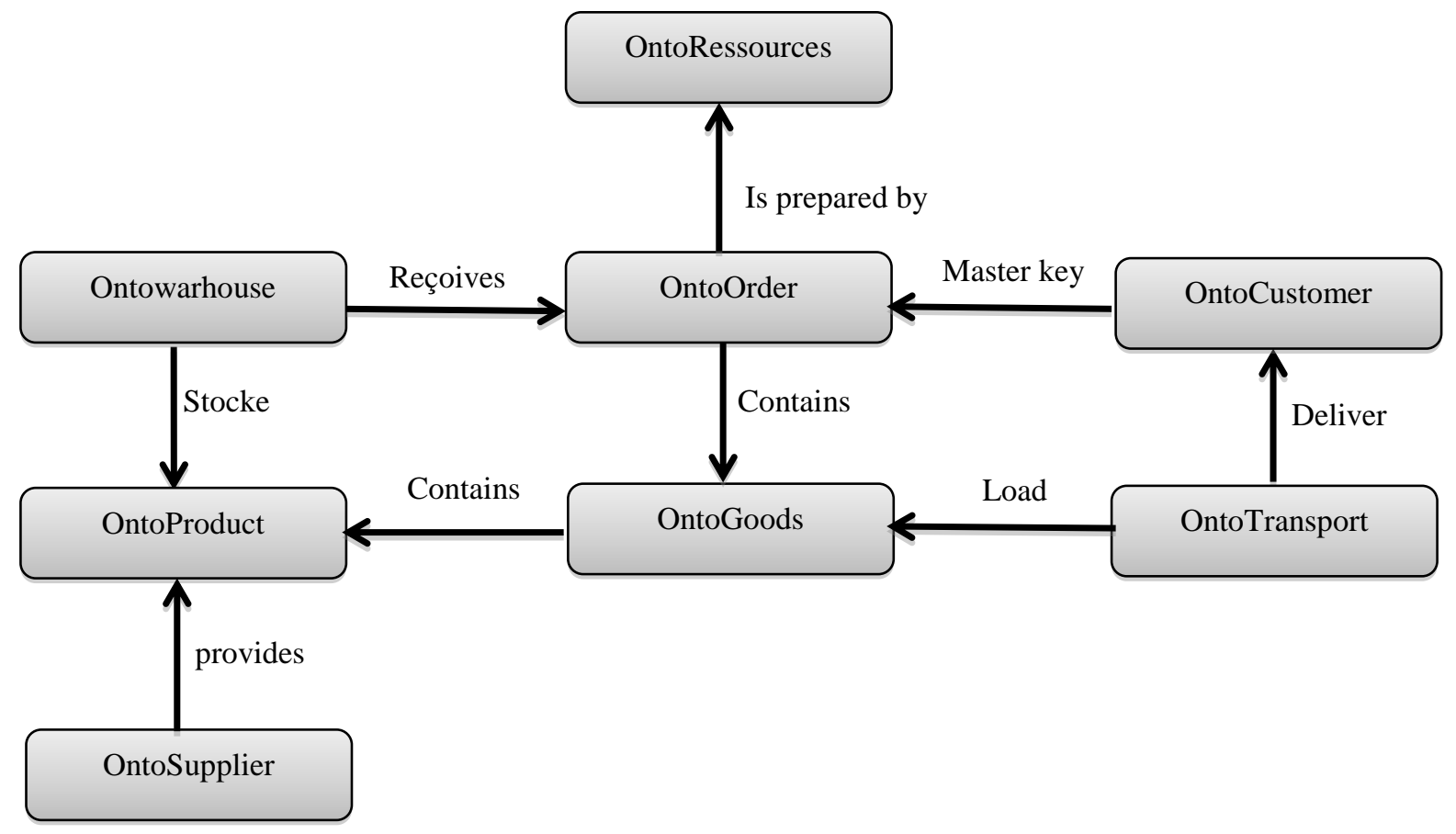

Fig 1: Relationship between different ontologies developed 


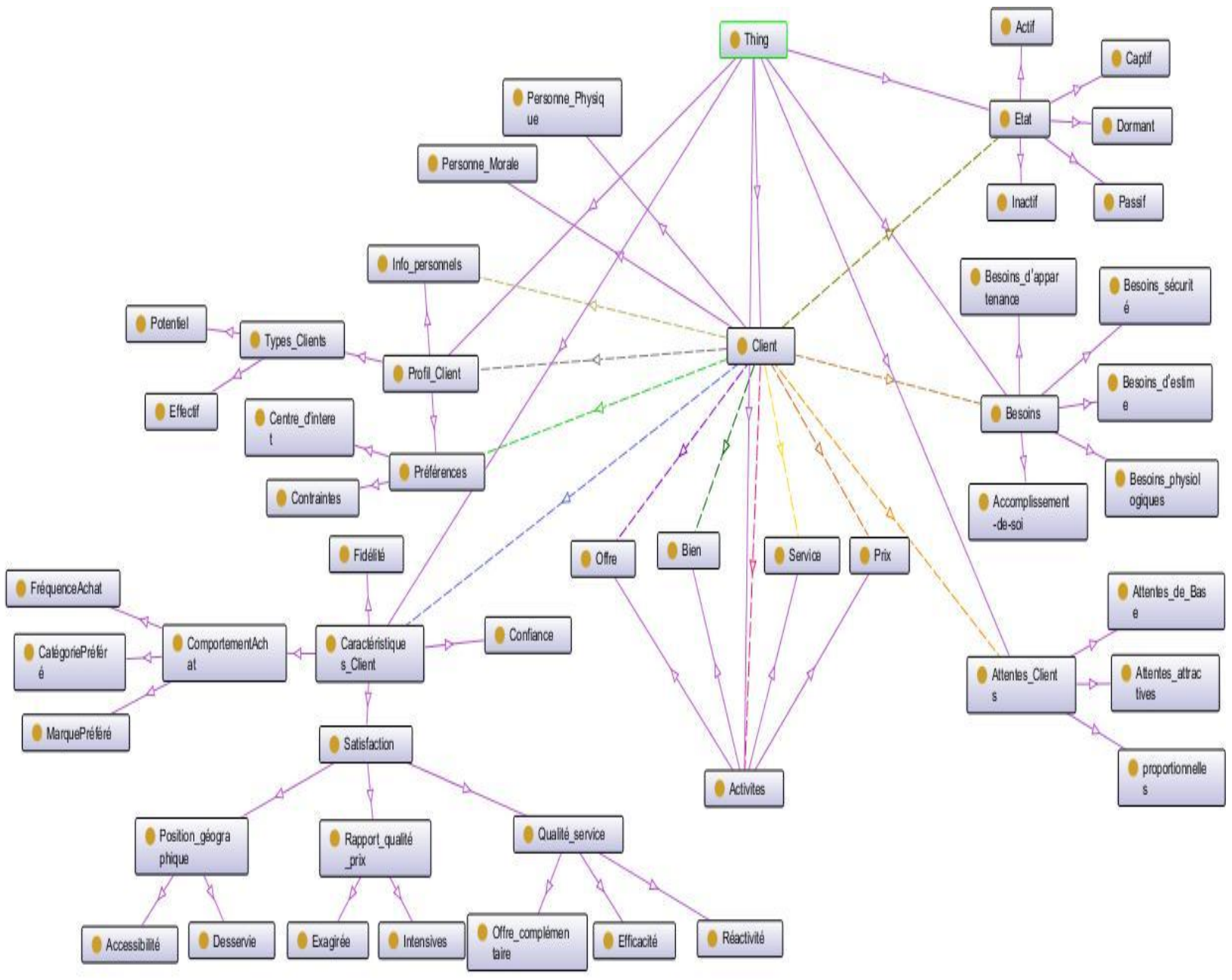

Fig 2: relationship Concept Concept customer model presented by OntoGraf of Protégé 2000

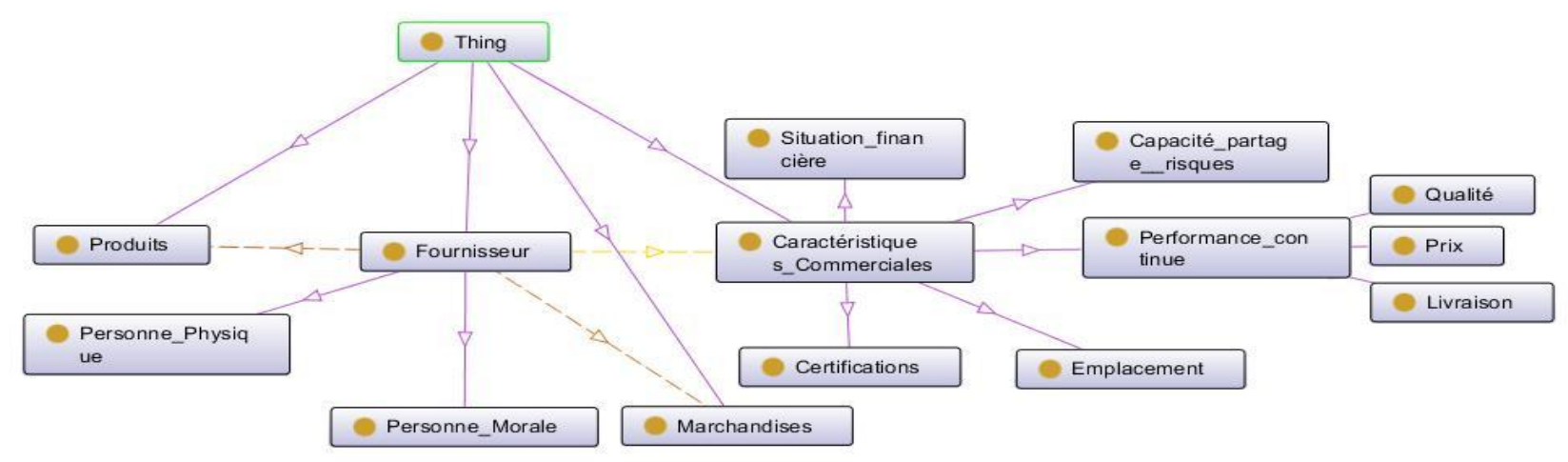

Fig 3: Relationship Concept Concept Supplier Model presented by OntoGraf of Protégé 2000 


\subsection{Order ontology}

Ontology order (Figure 4) is an ontology that allows defining the needed terminology for orders description. An order is a verbal or written intention to initiate a transaction. It is the action to request merchandise or services placed by a customer to a supplier

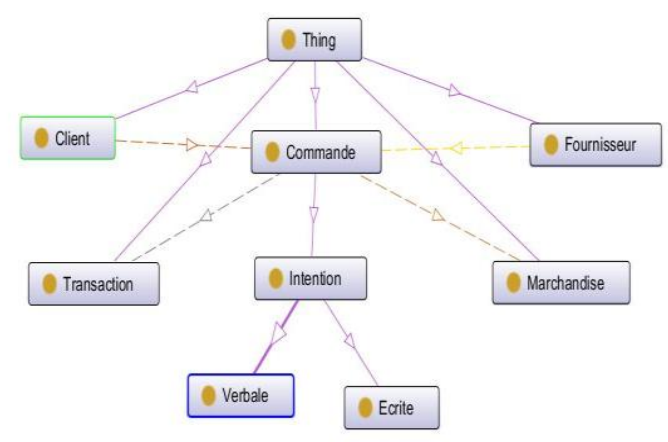

Fig 4: Relationship Concept-Concept for model of the control presented by OntoGraf of Protégé 2000

\subsection{Ontology product}

A product can be a physical product or service, this ontology defines product classification: raw material, semi-finished product, finished product and service (Figure 5).

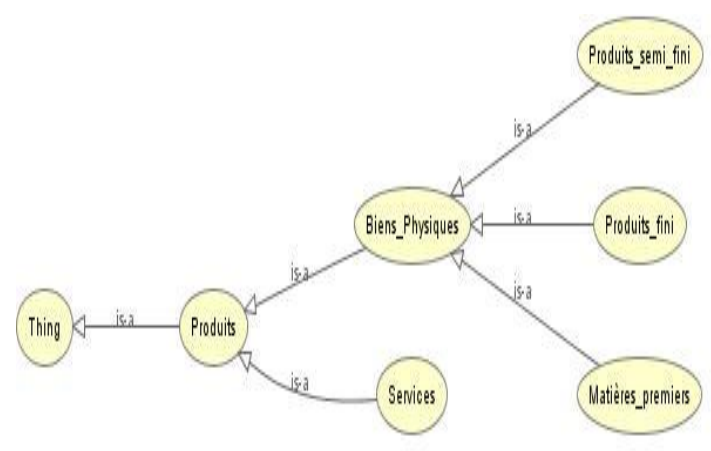

Fig 5: Classification of Products presented by OWLViz Protégé 2000

\subsection{Warehouse ontology}

Ontology warehouse (Figure 7) is an ontology that permits to define the needed terminology for describing warehouses. The warehouse is a storage place that receives different types of products, while responding to strict rules. It is a room for managing the flow of goods that has the following functions: reception, storage, order picking and delivery.

There are four main types of warehouse: Factory warehouse, retailer warehouse, distribution warehouse and central warehouse.

The warehouse infrastructure is composed of: building, storage rooms, social and health facilities, offices, bedrooms and docks for loading and unloading

\subsection{Ontology transport}

Transport ontology (Figure 8) is an ontology that permits to define the needed terminology for describing a transport. Freight transport is a regulated economic activity, both at national and international level. The moral or physic person who transport goods, called transporter, use means of transportation (cars, trains, cargo bike, aircraft, ships, etc.) and infrastructure formed by:

- $\quad$ Traffic routes (roads, railways, canals, rivers, ...)

- Amenities: car parks, ports, airports, etc.

- Structures, intended to overcome natural obstacles (bridges, overpasses, tunnels, locks, etc.).

According to the belonging of the means of transport (vehicle driver), type of freight is different: Transportation for the own account or transport for others.

\subsection{Resources ontology}

The ontology of resources (Figure 9) is an ontology that defines the classification of the warehouse resources. It has the resources that can be classified into three categories: financial, material resources, and human resources

\subsection{Merchandise ontology}

Merchandise is an object, a product that sells or buys, roughly, or in detail. Ontology Merchandise (Figure 6) allows the classification of different Merchandise: exceptional Merchandise, dry Merchandise, packaged Merchandise, general merchandise, heavy merchandise, and dangerous merchandise

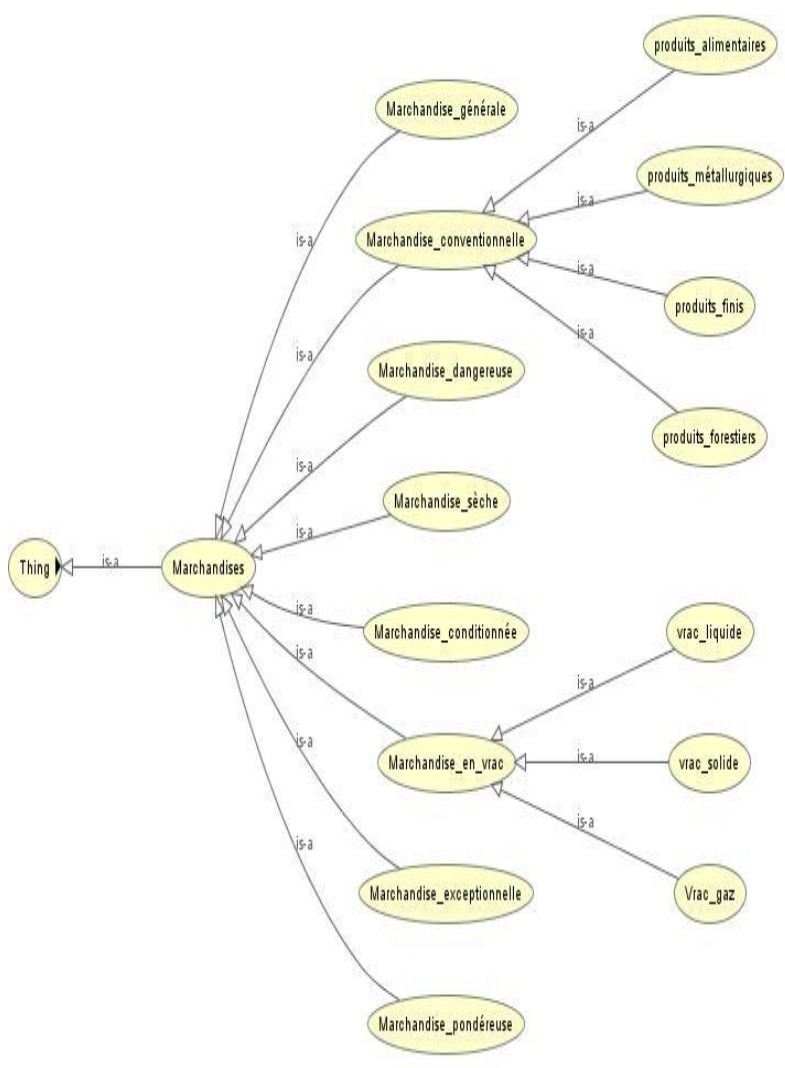

Fig 6: Ontology merchandise presented by OWLViz of Protégé 2000 


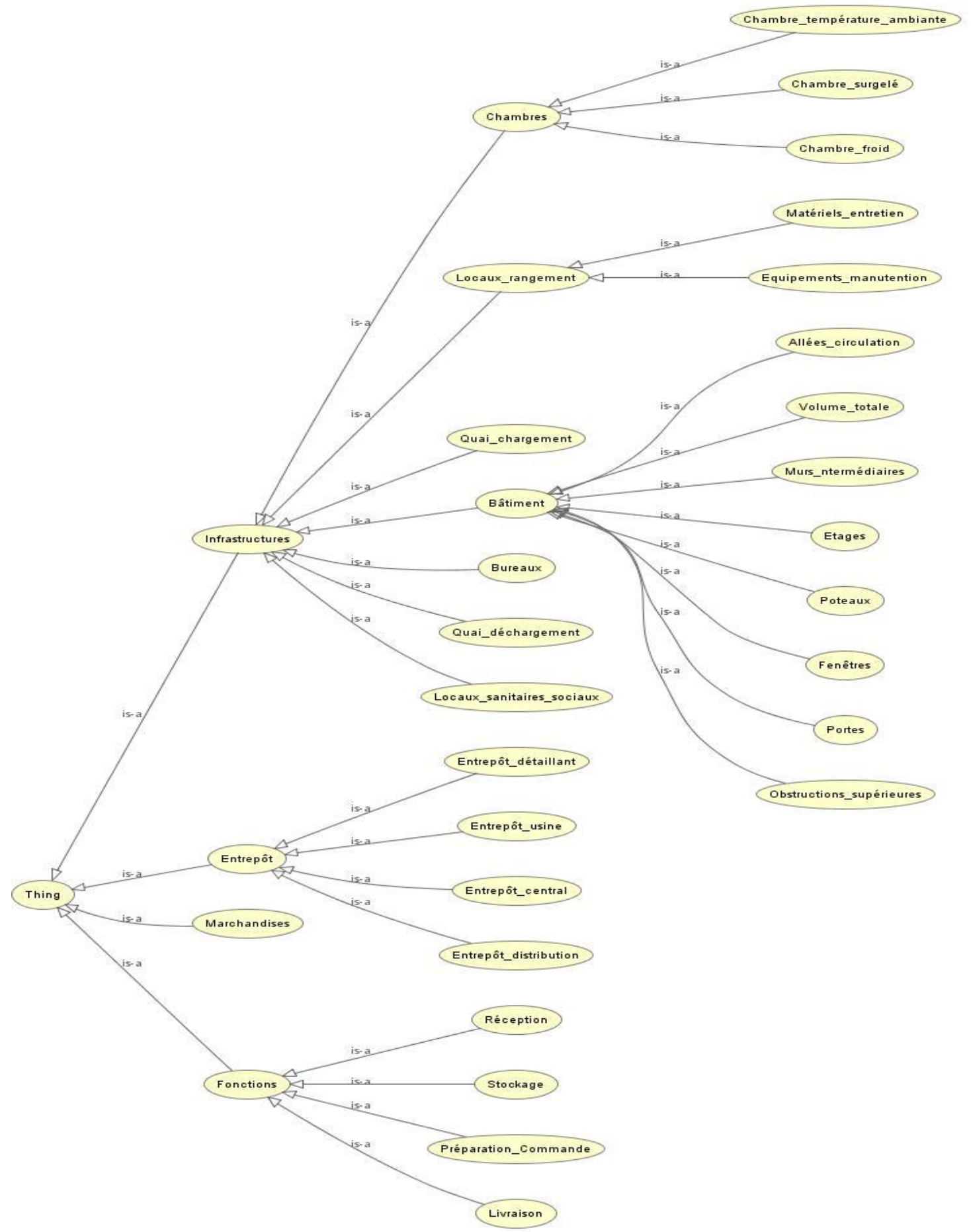

Fig 7: warehouse ontology presented by OWLViz of Protégé 2000 


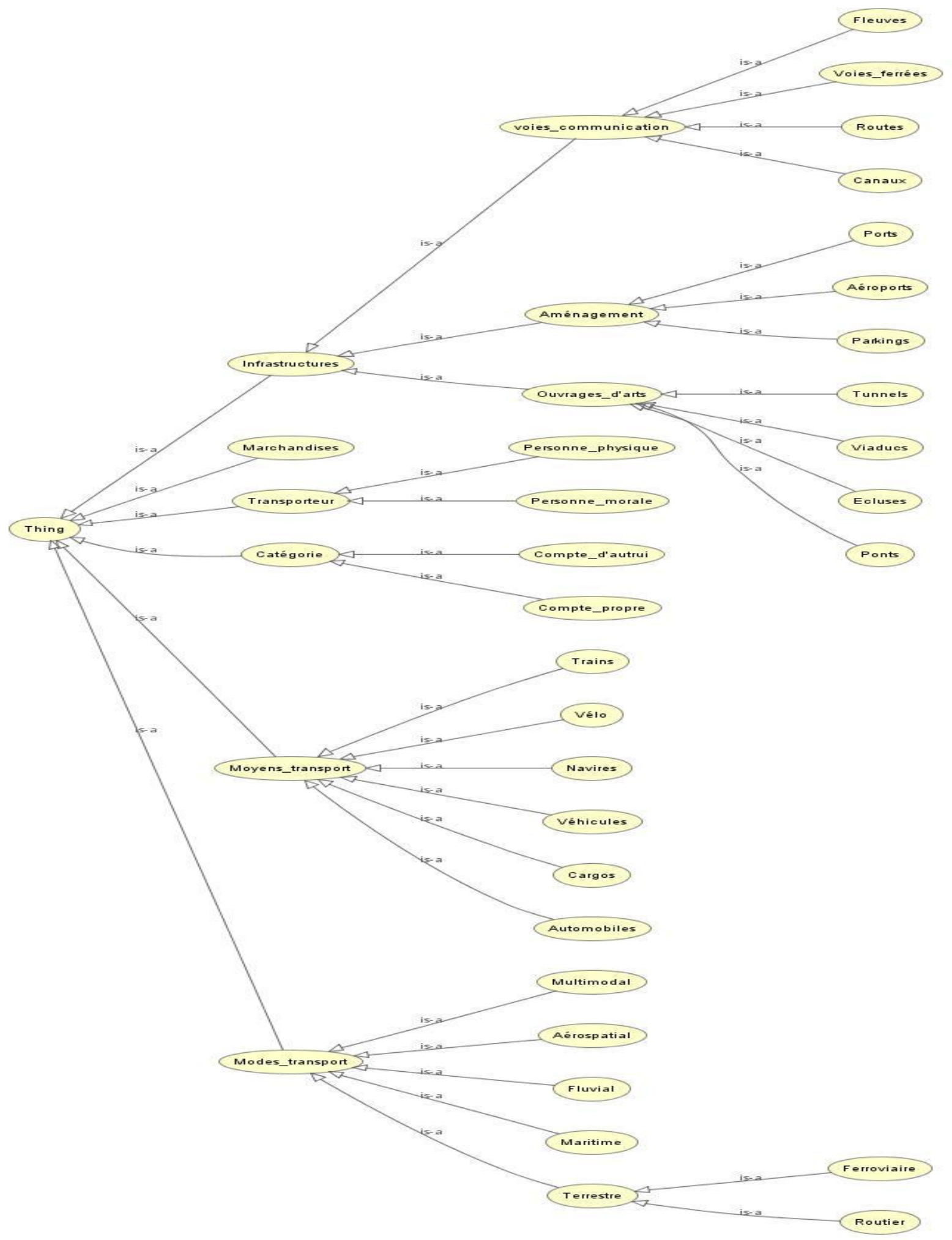

Fig 1 : Ontology transportation presented by OWLViz of Protégé 2000 


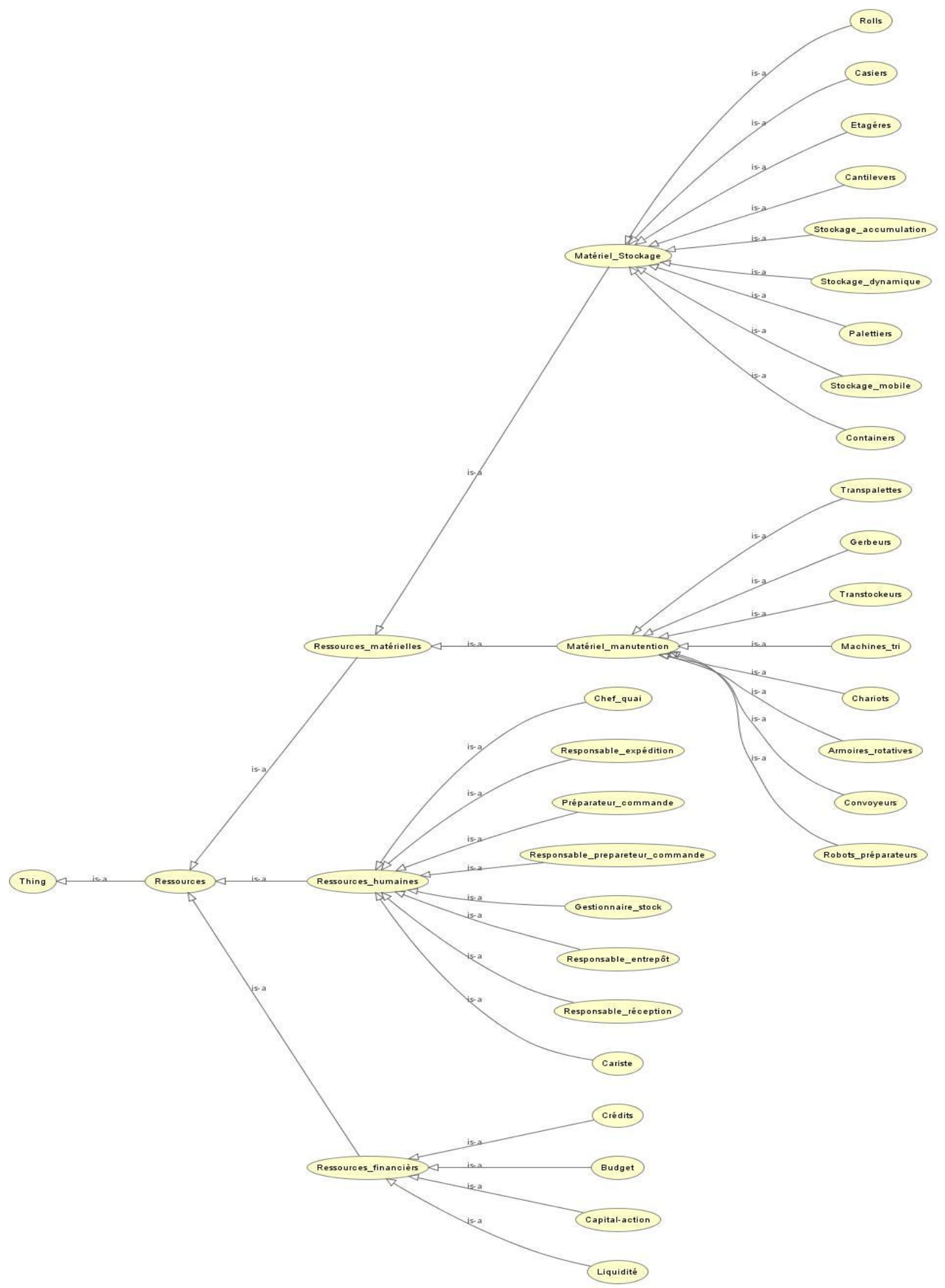

Figure 2 : Ontology resources presented by OWLViz of Protégé 2000 


\section{CONCLUSION ET PERSPECTIVES}

In this paper, we proposed a multi-ontologies system representing the information flow within the warehouse, to facilitate the exploitation of information, and ensure understanding of the contents of the exchanged messages between the system agents and the supply chain actors. We have presented eight ontologies; each one is related to a category of information that describes the inner functioning of the warehouse. The described ontologies are: warehouse ontology, customer ontology, supplier ontology, transport ontology, order ontology, Goods ontology, product ontology, and resource ontology. We adopted the methodology of the construction from text to define classes and their hierarchy for each ontology, and we implemented them in the editor Protégé 2000 version 4.3, which opens horizons to export these ontologies according to different languages (including OWL ), and import plugins to facilitate handling of ontologies (Framework Jena pour handling Owl files).

This result is the first version of the developed ontologies, which we will incorporate into a decision-making system (based on multi-agent systems) of management of warehouse, to ensure consistent and harmonious communications between the various entities of the system.

The designed ontologies, constitutes the semantic layer of the architecture of our system, they will be used on two levels initially, to model various information of the system, and then, to define the semantic relations between the knowledge formalized in the various knowledge bases from the agents in order to eliminate the conceptual and terminological confusion that might occur during communication between the agents.

\section{REFERENCES}

[1] R. M. et L. Tong, Optimisez votre plate-forme logistique, Les Editions d'Organisation, 2007.

[2] Y. Pimor et Michel Fender., LOGISTIQUE : Production Distribution Soutien, 5e édition, Dunod, 2008.

[3] Bakkali. H, Azmani. A et Fenan. A, «Dynamic Allocation of Products to Storage Areas in the Warehouse,» International Journal of Computer Applications (IJCA), vol. 84, n 16, pp. 36-43, 2013.

[4] Bakkali. H, Azmani. A et Fenan. A, «Organisation modulaire d'entrepôt,» colloque international veille stratégique scientifique et technologique,, Ajaccio France, le 25 Mai 2012..

[5] Bakkali. H, Azmani. A et Fenan. A, «Modeling of the Physical Flow of Goods within the Warehouse by the Hierarchical Coloured Petri Nets », International Journal of Advanced Research in Computer Science and Software Engineering, vol. 3, n¹9, 2013.

[6] A. David et E. Sutter, La gestion de l'information dans l'entreprise. BBF, 1985

[7] C. Gaumand, «Système de gestion des connaissances dédié à la chaine logistique : une recherche intervention au sein de l'entreprise BonfiglioliTransmissions.,» thèse de doctorat, Ecole Centrale Paris, 2014.

[8] F. Amardeilh, «Web Sémantique et Informatique Linguistique : propositions méthodologiques et réalisation d'une plateforme logicielle.,» Thèse de doctorat, Université Paris X -Nanterre., Paris, 2007.

[9] T.Gruber, «Toward principle for the design of ontologies used for knowledge sharing,» Technical report KSL ${ }^{\circ}$ 93-04,Standford University, 1993.

[10] M. Uschold, «Building Ontologies: Towards an Unified Methodology.,» the 16th conference of the British Computer Society Specialist Group on Expert Systems, 1996.

[11] G. KASSEL, «Ontospec : une méthode de spécification semi-informelle d'ontologies.,» 13èmes Journées Francophones d'Ingénierie des Connaissances (IC'2002), Rouen, France, 2002.

[12] M. Mhiri et F. Gargouri, «Méthodologie de construction des ontologies pour la résolution de conflits des systèmes d'information.,» Technique et Science Informatiques, vol. 28, n \%110, pp. 1263-1287, 2009.

[13] V. T. Henry, «Construction d'ontologies à partir de textes : une approche basée sur les transformations de modèles,» thèse de doctorat de l' Ecole Nationale Supérieure de Mécanique et d'Aérotechnique, 2012.

[14] G. Zacklad, D. KASSEL et E. BOURIGAULT, «Collection Technique et Scientifique des Télécommunications,» Ingénierie des connaissances, évolutions récentes et nouveaux défis, Paris, Eyrolles , 2000, pp. 305-323.

[15] H. S. PINTO et J. P. MARTINS, «A methodology for ontology integration,» chez K-CAP '01: 1st international conference on Knowledge capture, New York, NY, USA. ACM, 2001.

[16] L. J. Grüninger M., «Ontology Applications and Design,» the ACM, pp.39-44, 2002.

[17] V. Psyché, O. Mendes et e. B. J., «Apport de l'ingénierie ontologique aux environnements de formation à distance,» Revue des Sciences et Technologies de l'Information et de la Communication pour l'Education et la Formation (STICEF), vol. 10, pp. 89-126, 2003

[18] M. Baziz, «Indexation conceptuelle guidée par ontologie pour la recherche d'information.,» Thèse de doctorat, Université Paul Sabatier,, 2005

[19] K. Ottens, « Un système multi-agent adaptatif pour la construction d'ontologies à partir de textes,» Thèse de doctorat de l'Université Paul Sabatier, Toulouse III, 2007. 
[20] V. Fortineau, «Contribution à une modélisation ontologique des informations tout au long du cycle de vie du produit,» Thèse de doctorat , ENSAM., Paris, 2013.

[21] G.Aldo, Nicolas, GUARINO, M. Claudio, O. Alessandro et S. Luc, «Sweetening ontologies with dolce,» Processdings of the International Conference on Knowledge Engineering and Knowledge Management (EKAW02), Octobre 2002

[22] M. S. FOX et M. GRUNINGER, «Enterprise modeling,» AI magazine, vol. 19, $n^{\circ} 13$, p. 109, 1998

[23] C.-E. Foveau, «Référentiels des compétences et des métiers : une approche ontologique,» Thèse de doctorat de l'université de savoie en cotutelle avec l'université de lausanne, 2007.

[24] M. Tétreault, « Modélisation d'une ontologie et conceptualisation d'une application sémantique dédiée au e-recrutement dans le domaine des technologies de l'information,», Mémoire en Sciences de la communication de l'Université de Montréal, 2012.

[25] D. Fensel, D. L. Mc Guiness, E. Schulten, W. K. Ng, G. P. Lim et G. \& Yan, «Ontologies and electronic commerce,» Intelligent Systems, IEEE, vol. 16, n 1 , pp. $8-14,2001$

[26] D. Rosaci, Sarnè et G. M., «Multi-agent technology and ontologies to support personalization in B2C ECommerce,» Electronic Commerce Research and Applications, vol. 13, n \%11, pp. 13-23, 2014.

[27] V. Tamma, S. Phelps, I. Dickinson et M. \& Wooldridge, «Ontologies for supporting negotiation in e-commerce.,» Engineering applications of artificial intelligence, vol. $18, n^{\circ} \% 12$, pp. 223-236, 2005

[28] A.BENAYACHE, «Construction d'une memoire organisationnelle de formation et evaluation dans un contexte e-learning : le projet memorae,» Thèse de doctorat de l'université de technologie de compiegne, 2005.

[29] J. EL BOUHDIDI, «Une Architecture Intelligente Orientée Objectifs basée sur les Ontologies et les Systèmes Multi-agents pour la Génération des Parcours d'Apprentissage Personnalisés,» Thèse de doctorat de l'université Abdelmalek Essaâdi, Tanger, 2013.

[30] B. Kamsu-Foguem, «An ontological view in telemedicine,» vol. 3, $\mathrm{n}^{\circ} \% 12,2014$. M. GHAILANI, «Modélisation d'un système e-learning adaptatif orienté compétences basé sur l'ingénierie ontologique et les systèmes multi agents,» Thèse de doctorat de l'université Abdelmalek Essaâdi, Tanger, 2014.

[31] E. H., A. Sekkaki, A. B. Hajjam, T. L. et E. \& Andrès, «Ontologies et intégration des connaissances pour un suivi polypathologique.,» Médecine thérapeutique, vol. $20, n^{\circ} \% 12$, pp. $67-78,2014$

[32] B. Kamsu-Foguem, «An ontological view in telemedicine,» European Research in Telemedicine/La Recherche Européenne en Télémédecine, vol. 3, n%12, pp. 67-76, 2014.

[33] A. K. Wong, J. H. Wong, W. W. Lin, T. Dillon et E. \& Chang, Semantically Based Clinical TCM Telemedicine Systems, 2015.

[34] P. Borst et H.Akkermans, «Engineering ontologies.,» International Journal of Human-Computer Studies, vol. $46, n^{\circ} \% 12$, pp. $365-406,1997$

[35] T. Gruber et G. Olsen, «An Ontology for Engineering Mathematics.,» chez the Fourth International Conference on Principles of Knowledge Representation and Reasoning,, Morgan Kaufmann,, 1994.

[36] K. k et 1. S, «Building a large Scale Knowledge base for Machine Translation. Proceedings of the National Conference on Artificial Intelligence,» chez proceedings of the national conference o artificial intelligence, 1994.

[37] E. Viegas, «An Overt Semantics with a Machine-guided Approach for robust LKBs,» chez Proc. of SIGLEX99 Standardizing Lexical Resources., university of Maryland, 1999.

[38] C. Pesquita, D. Faria, A. O. Falcao, P. Lord et F. M. Couto, «Semantic similarity in biomedical ontologies.» PLoS computational biology, vol. 5, $\mathrm{n}^{\circ} \% 17,2009$.

[39] J. Swan, F.Trawick et D.Silva, «How industrial sales people gain customer trust.,» Industrial Marketing Management, vol. 14, $\mathrm{n}^{\circ}$ 3, pp. 203-211, 1985

[40] W. L. Wikie, Consumer Behavior, vol. Third Edition, canada, 1994.

[41] R.-M. Züger, Gestion d'entreprise-Compétences de base en gestion., Compendio Bildungsmedien AG,, 2011.

[42] X. DIANOU, «L'identification de la contribution des éléments de qualité à la satisfaction: le problème de la formulation des items dans le cadre d'un questionnaire Kano.,» La Revue des Sciences de Gestion, vol. 242, ${ }^{\circ}$ 2, pp. 87-92., 2010. 